\title{
Approach to low back pain in conservative societies and developing countries
}

\author{
Saif Aldeen AlRyalat ${ }^{1 *}$, Nosaiba Al-Ryalat ${ }^{2}$ and Abdee Ryalat ${ }^{3}$ \\ ${ }^{1}$ Doctor in Medicine, University of Jordan, Amman, Jordan \\ ${ }^{2}$ Associate professor, University of Jordan, Amman, Jordan \\ ${ }^{3}$ Professor, King Hussein Cancer Center, Amman, Jordan
}

\begin{abstract}
Low back pain is one of the most common complaints, $2^{\text {nd }}$ only to upper respiratory infections. Most of the studies in this regard done on developed countries. Here, we will discuss the approach to a patient with low back pain emphasizing on the differences between the guidelines in general and its applicability in conservative societies in developing countries.
\end{abstract}

\section{Introduction}

Low back pain is known to be one of the most common causes of outpatient medical visits in most societies, but most research on the epidemiology, clinical presentation, burden, and psychosocial impact and management of LBP has been conducted in the developed countries; therefore, little is known about these issues in developing countries [1].

In a review article that studied the prevalence of low back pain in developing countries, they found lower rates of low back pain compared with developed countries [2]. In this same study, they also found a lower rate in rural areas compared with urban in developing countries; a finding that can be predicted by knowing that sedentary life style with its associated activities is risk factors for low back pain [3].

The general approach to low back pain, including diagnosis and management, is generally defined by guidelines of the American College of Physicians (ACP) [4], and the National Institute for Health and Care Excellence (NICE) [5]. These guidelines which are generally applicable in western societies are not fully applicable in conservative societies, mainly Middle Eastern societies. On the basis of our observation and clinical experience, we speculate that there is a considerable difference between current management of LBP in middle eastern countries and management recommended by recent evidence-based clinical practice guidelines $[4,5]$. In this study, we will discuss how to use the most recent guidelines in the management of low back pain in conservative societies.

\section{Discussion}

Both guidelines agree that the approach should begin by a detailed history and physical examination that can rule out non-mechanical causes of low back pain including neoplastic, infection, fracture, inflammatory, and emergency cases (Spinal canal stenosis and cauda equine syndrome) [5]. History and physical examination should also address the current degree of pain and function in order to compare with follow up visits. These are a universal beginning for any patient regardless its society. Sometime in conservative societies, history and physical exam can't be fully addressed, so imaging can be used more than western societies as a complement to the missing part [6]. Electromyography (EMG) can be used as a substitute to imaging especially if the main use of imaging is for reassuring the patient, it can also have a better sensitivity and specificity for disk herniation with an additional placebo effect as a reassuring method for patients $[7,8]$.

After excluding non-mechanical causes of low back pain, the management approach should begin first by addressing patient's concerns and expectations regarding his case and by explaining the nature of his pain with a reassuring explanation. Both ACP and NICE also agree that we should depend on non-pharmacological modalities of treatment for low back pain regardless its duration (acute, subacute, or chronic), bearing in mind that most of these modalities highly depend on the placebo effect. Figure 1 shows general modalities that can be used in mechanical low back pain management.

Superficial heat is good modality to begin with, especially if it was well explained by the treating physician. In conservative society, where the patients prefer a treatment that can be continued at home, especially in females, superficial heat can be a convenient choice. Massage is another modality suggested by both guidelines, which can be combined with superficial heat to provide the best results.

Surface Electromyographic (SEMG) Biofeedback is a sophisticated process in which biological information is measured and fed back to a patient and clinician for the purpose of gaining increased awareness and control over physiological domains [7]. SEMG measure muscle activity, which allows both patient and clinician to gain an immediate access to muscle functioning that, is not possible with manual palpation. SEMG biofeedback can help "down-train" elevated muscle activity or "up-train" weak muscles.

Correspondence to: Saif Aldeen AlRyalat, Doctor in Medicine, University of Jordan, Amman, Jordan, E-mail: saifryalat@yahoo.com

Key words: low back pain, guidelines, developing countries, conservative societies Received: May 20, 2017; Accepted: June 16, 2017; Published: June 19, 2017 


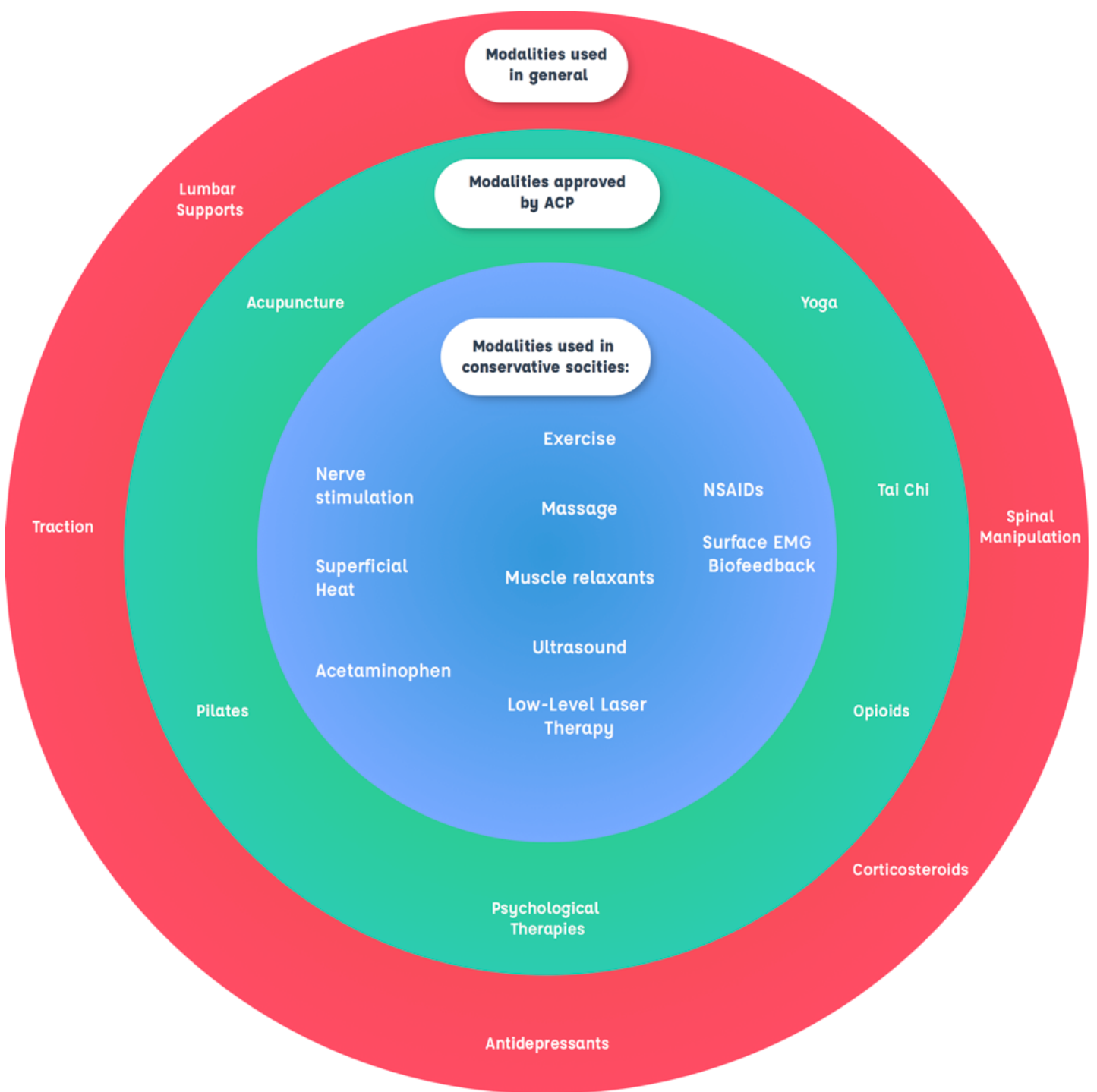

Figure 1. The inner circle (blue) shows modalities approved by ACP (American Collage of Physicions) and can be used in conservative societies, the next circle (green) include all modalities approved by ACP, the biggest circle (red) include all modalities in general used for low back pain.

Low level laser therapy, ultrasound, and nerve stimulation are modalities that are only recommended by ACP, they can have a strong placebo effect compared with heat and massage, but would be problematic in conservative societies as they require frequent clinic visits.

Yoga, Tai Chi, Pilates, Motor control exercise, and acupunctures will not be convenient in conservative societies, as the perception regarding these modalities will have a negative placebo effect, thus worsening their outcome. Another draw-back in these modalities is that they require frequent visits to group sessions, which won't be a good choice in conservative societies.

Psychological aspect is a major part in the management of low back pain in most western societies, which first require the use of depression screening questionnaires [9], but the screen for psychological aspect require the presence of sophisticated psychological management plan for the patients including the use of cognitive based therapy, mindfulness therapies [10]. In developing countries, these modalities are not always present, so addressing the yellow flags and managing them as possible will be more convenient than depression screening.

Pharmacological therapy including acetaminophens, non-steroidal anti-inflammatory drugs (NSAIDs), muscle relaxants, and opioids should be the second line in low back pain management, especially in developing countries, as their side effects are not considered by the patients, putting them on their long term side effects [4]. Physicians, on the other hand, should take advantage of the placebo effect of these drugs by combining the safest drug acetaminophens with the more effective drugs NSAIDs, thus minimizing the harm of long term NSAIDs use. Opioids should not be used except in the extreme situation where the physician can make sure the patient will not end up as an opioid-dependent patient.

\section{Conclusion}

Low back pain in developing countries is one of the most common causes outpatient visits, although less common than in developed countries. The general approach of low back pain in conservative 
societies in developing countries is different than the approach in the guidelines developed by western countries, an approach that is more convenient to its needs.

\section{Conflict of interest}

All authors declare no conflict of interest regarding this work.

\section{References}

1. Dagenais S, Caro J, Haldeman S (2008) A systematic review of low back pain cost of illness in the United States and internationally. Spine J 8: 8-20. [Crossref]

2. Volinn E (1997) The Epidemiology of Low Back Pain in the Rest of the World: A Review of Surveys in Low-and Middle-Income Countries. Spine 22: 1747-1754. [Crossref]

3. Chen SM, Liu MF, Cook J, Bass S, Lo SK (2009) Sedentary lifestyle as a risk factor for low back pain: a systematic review. International Archives of Occupational and Environmental Health 82: 797-806. [Crossref]
4. Qaseem A, Wilt TJ, McLean RM, Forciea MA (2017) Noninvasive Treatments for Acute, Subacute, and Chronic Low Back Pain: A Clinical Practice Guideline From the American College of Physicians Noninvasive Treatments for Acute, Subacute, and Chronic Low Back Pain. Annals of Internal Medicine 166: 514-530. [Crossref]

5. NNational GC (2016) Low Back Pain and Sciatica in Over 16s: Assessment and Management. [Crossref]

6. Mousavi SJ, Akbari ME, Mehdian H, Mobini B, Montazeri A, et al. (2011) Low back pain in Iran: a growing need to adapt and implement evidence-based practice in developing countries. Spine 36: E638-46. [Crossref]

7. Neblett R (2016) Surface electromyographic (SEMG) biofeedback for chronic low back pain. InHealthcare Multidisciplinary Digital Publishing Institute 4: 2-27. [Crossref]

8. Haig AJ Electromyography and Low Back Pain. Back Pain: A Guide for the Primary Care Physician. 2005:213.

9. Hiyama A, Watanabe M, Katoh H, Sato M, Sakai D, et al. (2016) Effect of depression and neuropathic pain using questionnaires on quality of life in patients with low back pain; cross-sectional retrospective study. European Spine Journal 25: 2750-2760. [Crossref]

10. Bushnell MC, Čeko M, Low LA (2013) Cognitive and emotional control of pain and its disruption in chronic pain. Nature reviews. Neuroscience 14: 502. [Crossref]

Copyright: (02017 AlRyalat SA. This is an open-access article distributed under the terms of the Creative Commons Attribution License, which permits unrestricted use, distribution, and reproduction in any medium, provided the original author and source are credited. 